\title{
Malignization of Oral Leukoplakia and the Need for Early Excisional Biopsy
}

\author{
Ju Hyung Jeong, Jun Wan Park, Ji Ryong Kim, Ki Ho Bae, Tae Woo Gim, and Chang Ki Yeo \\ Department of Otorhinolaryngology, School of Medicine, Keimyung University, Daegu, Korea
}

구강 내 백반증의 악성화와 조기 절제 생검의 필요성

정주형 - 박준완 - 김지룡 - 배기호 - 김태우 - 여창기

계명대학교 의과대학 이비인후과학교실

\author{
Received July 3, 2018 \\ Revised August 31, 2018 \\ Accepted September 10, 2018 \\ Address for correspondence \\ Chang Ki Yeo, MD, PhD \\ Department of Otorhinolaryngology, \\ School of Medicine, \\ Keimyung University, \\ 56 Dalseong-ro, Jung-gu, \\ Daegu 41931, Korea \\ Tel $+82-53-250-7711$ \\ Fax $+82-53-256-0325$ \\ E-mail ckyeo@dsmc.or.kr
}

Background and Objectives Cancer of the oral cavity is a disease of the head and neck that is difficult to treat. Periodic observation and biopsy are important for its early diagnosis once a premalignant lesion in the oral cavity is confirmed. The purpose of this study was to determine the importance of early excisional biopsy by investigating the histological features of oral leukoplakia and the rate of malignant change in the oral cavity.

Subjects and Method A total of 327 patients who underwent punch biopsy of oral cavity from January 2011 to December 2017 were reviewed retrospectively for the presence of initial gross lesions and for their biopsy results. The histological findings of 6 initial gross lesion groups were compared. Additional excisional biopsies were performed in the seven oral cavity subsites. Results There were 33 cases of oral leukoplakia. The punch biopsies of 3 of these cases (9.1\%) showed malignancy. Additional excisional biopsies were performed in 6 cases, 4 of which were malignant (66.7\%). Additional excisional biopsies of the tongue were performed in 14 cases $(9.0 \%), 5$ of which $(35.7 \%)$ were malignant. The rate of atypia in leukoplakia $(9.1 \%)$ was higher than in other atypia groups. Additional excisional biopsies were performed in 3 cases $(100 \%)$ of atypia of leukoplakia, all of which were assessed to be malignant.

Conclusion For tongue leukoplakia, performing an early excisional biopsy rather than an incisional biopsy is recommendable. Moreover, additional excisional biopsies are needed when the initial biopsy is suggestive of hyperkeratosis, parakeratosis, or atypia.

Korean J Otorhinolaryngol-Head Neck Surg 2019;62(2):108-13

Key Words Atypia · Biopsy · Early excision · Oral leukoplakia · Tongue.

\section{서 론}

악성 종양의 치료에 있어 조기 발견은 매우 중요하다. 하지 만 조기 발견이 모든 악성 종양에 같은 결과를 기대할 수는 없다. 인두, 후두 등과 같은 기관은 조기 발견이 생존율 및 사망률과 관계가 있으나 폐와 같은 기관은 금연과 같은 일차 예방만이 긍정적인 결과를 기대할 수 있다. 그렇다면 구강에

This is an Open Access article distributed under the terms of the Creative Commons Attribution Non-Commercial License (https://creativecommons.org/licenses/by-nc/4.0) which permits unrestricted non-commercial use, distribution, and reproduction in any medium, provided the original work is properly cited.
서는 어떠할까?

구강은 우리 몸의 영양을 공급하는 첫 번째 기관으로서 음식물 섭취와 발음에 중추적인 역할을 한다. 그렇기 때문에 구강에 생긴 병변은 단지 구강의 문제뿐만이 아니라 우리 몸 의 전반적인 상태에 영향을 줄 수 있어 적극적인 치료가 필 요하다. 그중에서도 구강의 악성 종양은 치료 후에도 구강의 기능 장애가 발생하여 삶의 질이 떨어지게 되는 경우가 많아 더욱 주의를 요한다.

구강암은 전 세계적으로 매년 30만 명이 진단받으며, 한 해 에 14 만 5 천 명이 구강암으로 인해 사망한다. ${ }^{1)}$ 이 중 $55 \%$ 가 
조기 병변(I, II 병기)으로 발견되며 남자, 흑인, 65 세 이상 환 자군에서 예후가 안 좋은 것으로 알려져 있다. ${ }^{2)}$ 우리나라에 서는 국립암센터에서 발표한 2015년 암 등록 통계에 의하면 전체 암 발생 중 구강암은 $0.65 \%$ 를 차지하였고 남성 대 여성 의 비는 $1.76: 1$ 로 남성에서 좀 더 많이 발생하였다. ${ }^{3)}$

구강암은 예후가 좋지 않고 치료 후 발생하는 구강의 기능 장애 때문에 예방적 치료 및 진행암 이전의 조기 발견이 무엇 보다도 중요하다. 이러한 과정에서 구강의 백반증은 대표적인 전암성 병변으로 알려져 있다. 일반적으로 구강 내 백반증이 발견되면 먼저 흡연 등의 유발 인자를 제거하면서 경과 관찰 을 하고, 그 후에도 병변이 지속되면 진단을 위한 추가 검사 를 하는 것이 권유되어 왔다. 그러나 본원에서 경험한 구강 병 변의 경우, 초기 생검상 양성이었으나 추후에 악성으로 진단 되어 치료 시기가 지연되는 경우가 있었다. 그리하여 본 연구 에서는 구강 백반증 환자의 증례들을 모아 임상적 특징을 비 교하고 구강 내 백반증 환자에서 펀치 생검보다 좀 더 적극적 인 완전한 절제 생검의 필요성에 대해 문헌 고찰과 함께 알아 보고자 한다.

\section{대상 및 방법}

2011년 1월부터 2017년 12월까지 계명대학교 동산의료원 이비인후과에 내원한 구강 내 병변 환자 중 임상적으로 악성 이 의심되는 전암성 병변 및 궤양, 종물 병변 등에서 펀치 생 검을 시행한 327 명의 환자를 대상으로 하였다. 구강의 부위 는 입술(lip), 치조릉(alveolar ridge), 구강저(floor of mouth), 구강혀(oral tongue), 경구개(hard palate), 구후 삼각(retromolar trigone) 및 협부 점막(buccal mucosa)의 7개 영역으로 구분하였으며 육안적 초기 병변은 백반증(leukoplakia), 적 색반(erythroplakia), 궤양 병변(ulcerative lesion), 종물 병변 (mass like lesion), 색소침착 병변(oral pigmented lesion) 및 다른 양성 병변의 6 개의 영역으로 구분하였다. 초기 생검 결 과를 바탕으로 추가 절제 생검 여부, 추가 절제 생검까지의 기 간 및 초기 생검 결과와의 비교 등을 후향적으로 분석하였으 며, 추가 절제 생검은 임상적으로 악성이 의심되지만 초기 검 사에서 양성으로 나온 경우 또는 약 4주간의 경과 관찰 후에 도 임상경과 호전이나 증상의 호전이 없을 경우 시행하였다. 이를 토대로 육안적 초기 병변에 따른 악성 및 추가 악성 비 율, 구강의 부위별 악성 및 추가 악성 비율, 그리고 초기 생검 결과를 비교하여 추가 절제 생검 필요성 여부에 대해 결과를 확인하였다. 특히, 육안적 병변상 백반증은 다른 병변과 비교 하여 그 중요성에 대해 비교 분석하였다.

\section{결 과}

구강 내 이상 병변으로 인해 펀치 생검을 시행한 총 327 명의 환자의 평균 나이는 56세였으며, 초기 펀치 생검상 암으로 진 단된 환자는 15 예였고 추가 절제 생검상 암으로 확인된 환자 는 6예로, 암으로 진단된 총 환자수는 21예(6.4\%)였다.

\section{구강 백반증의 초기 조직학적 결과}

육안적 초기 병변상 구강 백반증은 33예로 확인되었으며 남 성 대 여성의 비는 $1.06: 1$, 평균 나이는 61세였다. 초기 조직학 적 결과는 Benign 13예, Hyperplasia 4예, Hyper/paraketatosis 6예, Dysplasia 4예, Atypia 3예, 그리고 Malignancy 3 예로 나타났다(Fig. 1).

\section{육안적 초기 병변별 악성 비율}

육안적 초기 병변별로 구분하였을 때 종물 병변이 $58.8 \%$ 로 가장 많은 비율을 차지하였고 다음으로 궤양 병변, 백반증 등 의 순이었다. 특히 33예에서 구강 내 백반증으로 인해 조직 검사를 시행 받았다. Table 1에서 보는 바와 같이 초기 병변별 로 생검 결과를 살펴보면 백반증의 악성 비율이 9.1\%(3예)로 상대적으로 높았고 궤양 병변이 5.9\%(6예), 종물 병변이 $2.8 \%(5$ 예)로 그 뒤를 따랐다. 조직 검사 결과에 따라 살펴보 면 백반증의 atypia 군의 비율이 다른 육안적 병변의 atypia 군 비율에 비해 가장 높은 결과(9.1\%)를 보였다(Table 1).

\section{육안적 초기 병변별 추가 악성 비율}

비록 펀치 생검에서 악성으로 나오지는 않았지만 경과 관찰 후에도 병변이 지속되는 경우 또는 임상적으로 악성이 의심되 어 추가 절제 생검을 한 경우는 22예(6.7\%)였다. Table 2는 초 기 병변별로 추가 절제 생검의 비율 및 추가 악성 비율을 확인 한 결과로 백반증에서 가장 많은 추가 악성 비율 $(66.7 \%, 4$ 예) 을 보였으며 궤양 병변에서도 $28.6 \%$ (2예)의 추가 악성이 확인 되었다. 그러나 다른 병변에서는 추가 절제 생검상 추가 악성

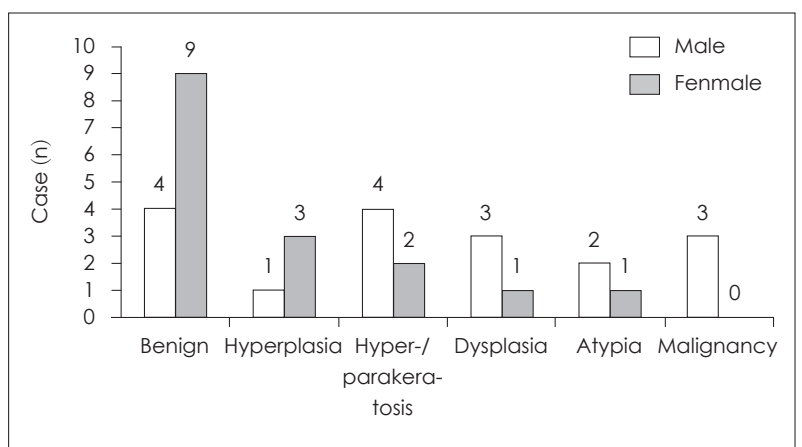

Fig. 1. Initial pathologic findings of oral leukoplakia. 
으로의 재확인은 관찰되지 않았다. 각각의 추가 절제 생검까 지의 평균 기간은 13 일에서 52 일까지, 전체 평균은 39.2 일이 었다(Table 2).

\section{구강 백반증의 초기 생검 결과별 추가 악성 비율}

Table 3은 구강백반증에 있어 초기의 펀치 생검별 결과에 따른 추가 악성 비율을 나타내는 자료로 조직 검사 결과상 hyperkeratosis, parakeratosis 및 atypia의 경우 모두 악성으 로 재확인됨을 보여주었다(100\%, 4예)(Table 3).

\section{구강의 부위별 초기 악성 비율}

초기 펀치 생검을 구강 부위별로 구분하였을 때 구강혀의 병
변이 가장 많았으며(47.7\%, 156예), 다음으로 입술, 협점막, 경 구개, 치조릉, 구강저 그리고 구후삼각 순이었다. 악성 비율은 구강저에서 $45.5 \%(5$ 예), 구후 삼각 $33.3 \%(1$ 예), 구강혀 5.8\% (9예), 협점막 $2.0 \%$ (1예)의 비율을 보였으며 펀치 생검상 hyperkeratosis/parakeratosisa 군은 구강혀에서 $7.7 \%$ 의 비교적 높은 비율로 확인되었다(Table 4).

\section{구강의 부위별 추가 악성 비율}

구강 부위별로 추가 절제 생검률을 비교하였을 때 구강저의 비율이 $18.2 \%$ (2예)로 가장 높았으나 구강혀의 병변 수가 가장 많아 추가 절제 생검은 구강혀 $(9.0 \%, 14$ 예)에서 가장 많이 시 행되었다. 추가 악성 비율 역시 구강혀에서 $35.7 \%$ (5예)로 가장

Table 1. Punch biopsy results by initial gross findings $(n=327)$

\begin{tabular}{|c|c|c|c|c|c|c|}
\hline & $\begin{array}{l}\text { Leukoplakia } \\
(n=33, \%)\end{array}$ & $\begin{array}{l}\text { Erythroplakia } \\
\qquad(n=3, \%)\end{array}$ & $\begin{array}{l}\text { Ulcerative lesion } \\
\qquad(n=101, \%)\end{array}$ & $\begin{array}{c}\text { Mass like lesion } \\
(n=176, \%)\end{array}$ & $\begin{array}{l}\text { Oral pigmented } \\
\text { lesion }(n=7, \%)\end{array}$ & $\begin{array}{l}\text { Others } \\
(n=7, \%)\end{array}$ \\
\hline Benign & $13(39.4)$ & 1 (33.3) & $63(62.4)$ & $138(78.4)$ & $7(100)$ & $4(57.1)$ \\
\hline Hyperplasia & $4(12.1)$ & $0(0)$ & $16(15.8)$ & $23(13.1)$ & $0(0)$ & $1(14.3)$ \\
\hline $\begin{array}{l}\text { Hyperkeratosis/ } \\
\text { parakeratosis }\end{array}$ & $6(18.2)$ & $1(33.3)$ & $3(3.0)$ & $8(4.5)$ & $0(0)$ & $0(0)$ \\
\hline Dysplasia & $4(12.1)$ & $1(33.3)$ & 8 (7.9) & $2(1.1)$ & $0(0)$ & $1(14.3)$ \\
\hline Atypia & $3(9.1)$ & $0(0)$ & $5(5.0)$ & $0(0)$ & $0(0)$ & $0(0)$ \\
\hline Malignacy & $3(9.1)$ & $0(0)$ & $6(5.9)$ & $5(2.8)$ & $0(0)$ & $1(14.3)$ \\
\hline
\end{tabular}

Table 2. Additional excisional biopsy and malignancy rates by initial gross findings $(n=22)$

\begin{tabular}{|c|c|c|c|c|c|c|}
\hline & $\begin{array}{l}\text { Leukoplakia } \\
\qquad(n=33, \%)\end{array}$ & $\begin{array}{l}\text { Erythroplakia } \\
\qquad(n=3, \%)\end{array}$ & $\begin{array}{l}\text { Ulcerative lesion } \\
\qquad(n=101, \%)\end{array}$ & $\begin{array}{l}\text { Mass like lesion } \\
\quad(n=176, \%)\end{array}$ & $\begin{array}{l}\text { Oral pigmented } \\
\text { lesion }(n=7, \%)\end{array}$ & $\begin{array}{l}\text { Others } \\
(n=7, \%)\end{array}$ \\
\hline Additional Bx rate & $6(18.2)$ & 1 (33.3) & 7 (6.9) & $7(4.0)$ & $0(0)$ & $1(14.3)$ \\
\hline $\begin{array}{l}\text { Additional } \\
\text { malignancy rate }\end{array}$ & $4 / 6(66.7)$ & $0 / 1(0)$ & $2 / 7(28.6)$ & $0 / 7(0)$ & $0(0)$ & $0 / 1(0)$ \\
\hline $\begin{array}{l}\text { Mean follow up } \\
\text { period (day) }\end{array}$ & 52 & 8 & 35.7 & 40 & - & 13 \\
\hline
\end{tabular}

Table 3. Comparison of the initial punch biopsy results and the additional excisional biopsy results in oral leukoplakia ( $\mathrm{n}=6$ )

\begin{tabular}{|c|c|c|c|c|c|}
\hline & $\begin{array}{l}\text { Benign } \\
(n=1, \%)\end{array}$ & $\begin{array}{l}\text { Hyperplasia } \\
\quad(n=0, \%)\end{array}$ & $\begin{array}{c}\text { Hyperkeratosis/ } \\
\text { parakeratosis }(n=1, \%)\end{array}$ & $\begin{array}{l}\text { Dysplasia } \\
(n=1, \%)\end{array}$ & $\begin{array}{l}\text { Atypia } \\
(n=3, \%)\end{array}$ \\
\hline Benign & $1(100)$ & - & $0(0)$ & $1(100)$ & $0(0)$ \\
\hline Sugestive malig & $0(0)$ & - & $0(0)$ & $0(0)$ & $0(0)$ \\
\hline Malignancy & $0(0)$ & - & $1(100)$ & $0(0)$ & $3(100)$ \\
\hline
\end{tabular}

Table 4. The initial punch biopsy results by oral cavity subsites $(n=327)$

\begin{tabular}{|c|c|c|c|c|c|c|c|}
\hline & $\begin{array}{c}\operatorname{Lip} \\
(n=74, \%)\end{array}$ & $\begin{array}{l}\text { Alveolar ridge } \\
\quad(n=15, \%)\end{array}$ & $\begin{array}{l}\text { Floor of mouth } \\
\qquad(n=11, \%)\end{array}$ & $\begin{array}{l}\text { Oral tongue } \\
(n=156, \%)\end{array}$ & $\begin{array}{l}\text { Hard palate } \\
(n=17, \%)\end{array}$ & $\begin{array}{c}\text { RMT } \\
(n=3, \%)\end{array}$ & $\begin{array}{c}\text { Buccal mucosa } \\
(n=51, \%)\end{array}$ \\
\hline Benign & 65 (87.8) & $11(73.3)$ & 3 (27.3) & $97(62.2)$ & $13(76.5)$ & 1 (33.3) & $36(70.6)$ \\
\hline Hyperplasia & $5(6.8)$ & $2(13.3)$ & $1(9.1)$ & $26(16.7)$ & $2(11.8)$ & $0(0)$ & $8(15.7)$ \\
\hline $\begin{array}{c}\text { Hyperkeratosis/ } \\
\text { parakeratosis }\end{array}$ & $1(1.4)$ & $0(0)$ & $0(0)$ & $12(7.7)$ & $0(0)$ & $1(33.3)$ & $3(5.9)$ \\
\hline Dysplasia & $2(2.7)$ & $1(6.7)$ & $2(18.2)$ & $7(4.5)$ & $2(11.8)$ & $0(0)$ & $2(3.9)$ \\
\hline Malignacy & $0(0)$ & $0(0)$ & $5(45.5)$ & $9(5.8)$ & $0(0)$ & 1 (33.3) & $1(2.0)$ \\
\hline Atypia & $1(1.4)$ & $1(6.7)$ & $0(0)$ & $5(3.2)$ & $0(0)$ & $0(0)$ & $1(2.0)$ \\
\hline
\end{tabular}

RMT: retromolar trigone 
높았고 그 외에는 입술에서 1 예를 제외하고 악성으로 재확인 되는 구강 부위는 관찰되지 않았다. 일반적으로 2 4주 경과 관찰 후 명확한 임상적 진단을 내려지게 되는데) 본 연구의 각 부위별 추가 절제 생검까지의 평균 기간은 13 일에서 42 일 까지의 분포를 보였다(Table 5).

\section{구강 백반증의 부위별 분포 및 추가 악성 비율}

백반증의 부위별 분포 결과를 살펴보면 구강혀에서 가장 많은 분포를 보였고 $(14.3 \%, 14$ 예) 구강혀의 초기 펀치 생검 결 과는 hyperkeratosis/parakeratosis 군이 가장 많은 비율을 보 였다(35.7\%, 5예)(Table 6).

백반증의 추가 절제 생검 결과에서 구강혀, 입술에서의 추
가 절제 생검이 각각 5 예, 1 예가 있었으며 추가 악성 비율은 각각 60\%(3예), $100 \%(1$ 예)로 확인되었다(Table 7).

\section{초기 생검 결과별 추가 악성 비율}

초기 펀치 생검 결과를 추가 절제 생검 결과와 비교 하였을 때 hyperkeratosis/parakeratosis 군, atypia 군에서 각각 $100 \%$ (2예), $80 \%$ (4예)의 추가적인 악성 비율을 보였다. 양성인 경 우는 추가 절제 생검하였을 때 모두 양성 병변으로 확인되었 고 의외로 dysplasia인 경우는 추가 절제 생검상 악성으로 재 확인되지는 않았다(Table 8). 구강 백반증의 경우 추가 절제 생검은 hyperkeratosis/parakeratosis 군, atypia 군에서 추가 절제 생검 결과 모두 악성으로 확인되었다(Table 3).

Table 5. Additional excisional biopsy and malignancy rates by oral cavity subsites $(n=327)$

\begin{tabular}{|c|c|c|c|c|c|c|c|}
\hline & $\begin{array}{c}\operatorname{Lip}_{(n=74, \%)} \\
\end{array}$ & $\begin{array}{l}\text { Alveolar ridge } \\
\quad(n=15, \%)\end{array}$ & $\begin{array}{l}\text { Floor of mouth } \\
\qquad(\mathrm{n}=11, \%)\end{array}$ & $\begin{array}{l}\text { Oral tongue } \\
(n=156, \%)\end{array}$ & $\begin{array}{l}\text { Hard palate } \\
(n=17, \%)\end{array}$ & $\begin{array}{c}\text { RMT } \\
(n=3, \%)\end{array}$ & $\begin{array}{c}\text { Buccal mucosa } \\
(n=51, \%)\end{array}$ \\
\hline Additional bx rate & $3(4.1)$ & $2(13.3)$ & $2(18.2)$ & $14(9.0)$ & 0 & 0 & $1(2.0)$ \\
\hline $\begin{array}{l}\text { Additional } \\
\text { malignancy rate }\end{array}$ & $1 / 3(33.3)$ & 0/2 (0) & 0/2 (0) & $5 / 14(35.7)$ & - & - & $0 / 1(0)$ \\
\hline $\begin{array}{l}\text { Mean follow up } \\
\text { period (day) }\end{array}$ & 36.7 & 42 & 38 & 41.4 & - & - & 13 \\
\hline
\end{tabular}

RMT: retromolar trigone

Table 6. Distribution of oral leukoplakia by oral cavity subsites and by initial punch biopsy results $(n=33)$

\begin{tabular}{|c|c|c|c|c|c|c|c|}
\hline & $\begin{array}{c}\operatorname{Lip} \\
(n=2, \%)\end{array}$ & $\begin{array}{l}\text { Alveolar ridge } \\
\quad(n=2, \%)\end{array}$ & $\begin{array}{l}\text { Floor of mouth } \\
\qquad(n=1, \%)\end{array}$ & $\begin{array}{l}\text { Oral tongue } \\
\qquad(n=14, \%)\end{array}$ & $\begin{array}{l}\text { Hard palate } \\
\quad(n=0, \%)\end{array}$ & $\begin{array}{c}\text { RMT } \\
(n=1, \%)\end{array}$ & $\begin{array}{c}\text { Buccal mucosa } \\
(n=13, \%)\end{array}$ \\
\hline Benign & $1(50)$ & $1(50)$ & $0(0)$ & $2(14.3)$ & - & $0(0)$ & $9(69.2)$ \\
\hline Hyperplasia & $0(0)$ & $1(50)$ & $0(0)$ & $1(7.1)$ & - & $0(0)$ & $2(15.4)$ \\
\hline $\begin{array}{r}\text { Hyperkeratosis/ } \\
\text { parakeratosis }\end{array}$ & $0(0)$ & $0(0)$ & $0(0)$ & $5(35.7)$ & - & $1(100)$ & $1(7.7)$ \\
\hline Dysplasia & $0(0)$ & $0(0)$ & $0(0)$ & $3(21.4)$ & - & $0(0)$ & $1(7.7)$ \\
\hline Malignacy & $0(0)$ & $0(0)$ & $1(100)$ & $2(14.3)$ & - & $0(0)$ & $0(0)$ \\
\hline Atypia & $1(50)$ & $0(0)$ & $0(0)$ & $1(7.1)$ & - & $0(0)$ & $0(0)$ \\
\hline
\end{tabular}

RMT: retromolar trigone

Table 7. Additional excisional biopsy results and malignancy rates by oral cavity subsites in oral leukoplakia $(n=15)$

\begin{tabular}{|c|c|c|c|c|c|c|c|}
\hline & $\begin{array}{c}\text { Lip } \\
(n=1, \%)\end{array}$ & $\begin{array}{l}\text { Alveolar ridge } \\
\quad(n=0, \%)\end{array}$ & $\begin{array}{l}\text { Floor of mouth } \\
\qquad(n=0, \%)\end{array}$ & $\begin{array}{l}\text { Oral tongue } \\
\qquad(n=14, \%)\end{array}$ & $\begin{array}{l}\text { Hard palate } \\
(n=0, \%)\end{array}$ & $\begin{array}{c}\text { RMT } \\
(n=0, \%)\end{array}$ & $\begin{array}{c}\text { Buccal mucosa } \\
(n=0, \%)\end{array}$ \\
\hline Additional Bx rate & $1(100)$ & - & - & $5(35.7)$ & - & - & - \\
\hline $\begin{array}{l}\text { Additional } \\
\text { malignancy rate }\end{array}$ & $1 / 1(100)$ & - & - & $3 / 5(60.0)$ & - & - & - \\
\hline $\begin{array}{l}\text { Mean follow up } \\
\text { period (day) }\end{array}$ & 38 & - & - & 54.8 & - & - & - \\
\hline
\end{tabular}

RMT: retromolar trigone

Table 8. Comparison of initial punch biopsy and additional excisional biopsy results $(n=22)$

\begin{tabular}{lccccc}
\hline & $\begin{array}{c}\text { Benign } \\
(\mathrm{n}=6, \%)\end{array}$ & $\begin{array}{c}\text { Hyperplasia } \\
(\mathrm{n}=5, \%)\end{array}$ & $\begin{array}{c}\text { Hyperkeratosis/ } \\
\text { parakeratosis }(\mathrm{n}=2, \%)\end{array}$ & $\begin{array}{c}\text { Dysplasia } \\
(\mathrm{n}=4, \%)\end{array}$ & $\begin{array}{c}\text { Atypia } \\
(\mathrm{n}=5, \%)\end{array}$ \\
\hline Benign & $6(100)$ & $5(100)$ & $0(0)$ & $4(100)$ & $1(20)$ \\
Sugestive malig & $0(0)$ & $0(0)$ & $0(0)$ & $0(0)$ & $0(0)$ \\
Malignancy & $0(0)$ & $0(0)$ & $2(100)$ & $0(0)$ & $4(80)$ \\
\hline
\end{tabular}




\section{고 찰}

구강의 전암성 병변은 일반적으로 매년 $0.29 \%$ 의 유병률을 보이며) 2010 년에 발표된 Liu 등ㅎㅇㅢ 연구에 따르면 50대에 유병률이 가장 높고 이전 연구에 비해 유발 연령이 낮아짐을 보고하고 있다. 이 중에서도 구강의 백반증은 구강의 전암성 병 변 중 가장 흔한 질환으로 중년 남성에게서 가장 흔히 발견되 나 30세 이전의 남성에게서는 덜 흔한 것으로 알려져 있다. ${ }^{7}$

구강의 백색 병변은 1870 년경 Paget에 의해 전암성 병변으 로 인식되었다. 처음에는 ichthyosis, smoker's patch, leucokeratosis 등으로 불리어졌으며, ${ }^{8}$ 백반증이라는 용어는 1877 년에 Schwimmer에 의해 처음으로 사용되었다. 현재 백반증 은 문질러서 지워지지 않는 점막의 백색 반상 병변이면서 다른 질환으로 설명되지 않는 임상적 병변을 의미한다. 조직학적으 로 1) simple orthokeratosis, 2) parakeratosis with epithelial hyperplasia and minimal inflammation, 3) hyperkeratosis with varying degrees of dysplasia로 분류되며") 악성화 진행 률은 일반적으로 $0.13 \sim 17.5 \%$ 로 알려져 있다. ${ }^{10)}$ 본 연구에서 도 양성 병변의 경우 병리 결과를 hyperplasia, hyperkeratosis and parakeratosis, dysplasia, atypia, 그리고 기타 양성 병변 으로 분류하여 비교하였다.

구강 백반증이 진단되는 것은 3 단계를 거쳐왔다. 구강 내 증상으로 인해 병원을 찾은 환자를 진찰했을 때 구강 내 백 색 병변이 발견되면 잠정적 진단(provisional diagnosis)이 내 려지게 된다. 백색 병변을 일으킬 만한 확실한 원인 인자가 없 는 경우이거나 흡연, 기계적 자극 등의 원인 인자를 제거한 뒤 2 4주 기다려 봐도 병변이 지속되는 경우에는 명확한 임 상적 진단(definite clinical diagnosis)이 내려지게 된다. 임상 적 진단이 내려진 뒤에는 생검을 통해서 이형성증이 있는 백 반증(dysplastic leukoplakia), 이형성증이 없는 백반증(nondysplastic leukoplakia), 기타 질병 등의 조직병리학적 진단 (histopathologically proven diagnosis)이 내려지며 각각의 특 성에 따라 치료가 이루어진다. ${ }^{4,11,12)}$

본 연구에서는 상기 기술된 원인 인자의 제거 후 기다리는 단계를 따르지 않고 임상적 진단 단계에서 바로 조직 검사를 시행하였다. 다만 초기에는 펀치 생검을 시행하였으며 악성 이 의심되나 명확하지 않은 결과를 보일 때는 약 4 주간의 경 과 관찰 후(Table 2, 5) 추가적으로 절제 생검을 시행하였다. 그 결과 hyperplasia, hyperkeratosis, dysplasia 등의 양성 병변 등도 발견되었으나 상피내암(carcinoma in situ), 편평세포암 (squamous cell carcinoma) 등의 악성 병변 역시 3예(9.1\%)나 확인되어 조기에 진단되는 효과가 있었다. 이에 더해서 백반 증의 추가 절제 생검은 6예(18.2\%)에 이루어졌으며 이중 4예
(66.7\%)에 악성이 추가적으로 확인되는 결과를 보여줬다. 이로 말미암아 구강 백반증의 진단적 관점에서 보면 악성 전환율 이 높지 않기 때문에 먼저 원인 인자를 제거해보고 경과를 관 찰하는 것이 필요 없는 진단적 시술을 줄이므로 합당할 수 있지만, 구강암의 관점에서 보면 잠정적 진단의 단계를 거치 지 않고 초기에 명확한 임상적 진단을 내려 바로 조직 검사 를 하는 것이 치료에 도움을 줄 수 있다고 생각되어진다. 또 한 본 연구에서도 확인되었듯이 백반증의 경우 초기 펀치 생 검보다 추가 절제 생검을 통해 더 많은 악성 증례를 확인할 수 있었다. 이로써 명확한 임상적 진단 단계에서 조직 검사를 시행할 시에는 펀치 생검과 같은 부분적 조직 검사보다 절제 생검이 진단에 더욱 도움이 될 것으로 보인다.

구강 백반증의 부위별 분포를 확인하였을 때 구강혀의 비 율이 가장 높은 결과를 보였다. 초기 조직 검사 결과상 hyperkeratosis/parakeratosis 군 역시 구강혀에서 가장 높은 비율 을 보였으며 이는 Liu 등하년구와 유사한 결과를 보였다. 또 한 백반증의 임상 양상을 보이는 환자의 초기 조직 검사 결과 상 hyperkeratosis/parakeratosis 군 및 atypia 군에서 육안적 으로 악성이 의심되어 시행한 추가 절제 생검상 모두 악성으로 재확인이 되는 것을 본 연구에서 발견하였다. 부위별 추가 절 제 생검에서도 백반증을 보이는 구강혀의 경우에서 3예(60\%) 에서 악성으로 확인되어 다른 부위에 비해 악성의 가능성이 높은 것으로 확인되었다. 그러나 일반적으로 높은 악성화를 보이는 dysplasia의 경우 추가 절제 생검이 1예에 그쳐 악성 재확인을 판단하기에 다소 무리가 있을 것으로 생각된다.

초기 조직 검사의 결과에 따른 추가 악성을 확인 한 본 연 구에서 흥미로운 결과를 확인할 수 있었다. 육안적 또는 임상 적으로 악성이 의심된다면 초기 조직 검사상 hyperkeratosis, parakeratosis 및 atypia의 추가 절제 생검상 적어도 $80 \%$ 이 상에서 악성이 재확인되었다는 점이다. 특히 구강 백반증의 atypia 경우 추가 절제 생검상 모두 악성으로 진단되는 결과 를 보여주었다.

이상의 결과를 토대로 구강 백반증의 적절한 진단적 시술 시점에 대한 결론은 높은 악성 비율을 감안하여 초기에 조 직 검사를 시행하는 것이 바람직하다고 보여진다. 그리고 나 아가 시술 시행 방법에 있어서는 부분적 조직 검사보다는 처 음부터 병변의 완전 절제 생검이 조기 진단 및 치료에 더 큰 도움을 줄 수 있음을 본 연구를 통해 확인하였다. 또한 구강 내 백반증을 부위별로 비교하였을 때 구강 내 병변 중 구강 혀에 발생하였을 경우 악성 비율이 높아 진단 시 적극적인 시술, 즉 완전 절제 생검이 필요함을 보여주었다. 그리고 초기 조직 검사에서 hyperkeratosis, parakeratosis, 그리고 atypia 의 결과가 나올 경우라도 육안적으로 악성이 의심된다면 더 
욱더 적극적인 추가 절제 생검이 필요함을 본 연구를 통해 확인할 수 있었다.

그러나 본 후향적 연구에서는 구강 백반증의 원인에 대한 조사 및 고찰에 대해서는 확인하지 못하였다. 그리고 추가 절 제 생검상 dysplasia의 악성은 확인되지 않았는데 이는 분화 도에 따른 조직학적 분류를 구분하지 않아 보여진 결과로 생 각된다. 그리고 후향적으로 진행된 본 연구 특성상 펀치 생검 과 절제 생검의 방법을 서로 비교 분석하기에는 한계가 있었으 며 향후 이에 대해서는 추가적인 연구가 필요할 것으로 보인다.

\section{REFERENCES}

1) Warnakulasuriya S. Global epidemiology of oral and oropharyngeal cancer. Oral Oncol 2009;45(4-5):309-16.

2) Funk GF, Karnell LH, Robinson RA, Zhen WK, Trask DK, Hoffman HT. Presentation, treatment, and outcome of oral cavity cancer: a National Cancer Data Base report. Head Neck 2002;24(2):165-80.

3) Ministry of Health and Welfare. Annual report of cancer statistics in Korea in 2015. Goyarg: National Cancer Center;2017. p.54-5.

4) Kumar A, Cascarini L, McCaul JA, Kerawala CJ, Coombes D, Godden
D, et al. How should we manage oral leukoplakia? Br J Oral Maxillofac Surg 2013;51(5):377-83.

5) Roy S, Varshney S. Oral dermatological conditions: a clinical study. Indian J Otolaryngol Head Neck Surg 2013;65(2):97-101.

6) Liu W, Wang YF, Zhou HW, Shi P, Zhou ZT, Tang GY. Malignant transformation of oral leukoplakia: a retrospective cohort study of 218 Chinese patients. BMC Cancer 2010;10:685.

7) Bouquot JE, Gorlin RJ. Leukoplakia, lichen planus, and other oral keratoses in 23,616 white Americans over the age of 35 years. Oral Surg Oral Med Oral Pathol 1986;61(4):373-81.

8) Bouquot JE, Whitaker SB. Oral leukoplakia--rationale for diagnosis and prognosis of its clinical subtypes or "phases." Quintessence Int 1994;25(2):133-40.

9) Tradati N, Grigolat R, Calabrese L, Costa L, Giugliano G, Morelli F, et al. Oral leukoplakias: to treat or not? Oral Oncol 1997;33(5):317-21.

10) Amagasa T, Yamashiro M, Uzawa N. Oral premalignant lesions: from a clinical perspective. Int J Clin Oncol 2011;16(1):5-14.

11) van der Waal I. Potentially malignant disorders of the oral and oropharyngeal mucosa; present concepts of management. Oral Oncol 2010;46(6):423-5.

12) Warnakulasuriya S, Johnson NW, van der Waal I. Nomenclature and classification of potentially malignant disorders of the oral mucosa. J Oral Pathol Med 2007;36(10):575-80. 